\title{
INTERCONDYLAR T-SHAPED FRACTURES OF THE HUMERUS
}

\author{
Results in Ten Cases Treated by Early Mobilisation
}

\author{
R. F. Brown, Sheffield, and R. G. Morgan, Slough, England \\ From St Peter's Hospital, Chertsey, and the Rowley Bristow Orthopaedic Hospital, Pyrford, Surrey
}

Intercondylar $\mathrm{T}$-shaped fractures of the humerus are caused by a force through the olecranon driving it upwards between the condyles of the humerus. Usually the patient has fallen on to the "point of the elbow". These injuries are uncommon, and no matter what treatment is used, perfect results are seldom obtained. This paper reports ten severe fractures of this type treated in a collar-and-cuff sling with early active movements. The method is not new-indeed a somewhat similar technique was used by $\mathrm{H}$. O. Thomas.

\section{MATERIAL}

Eleven patients with intercondylar T-shaped fractures of the humerus were treated during the four years 1965-68. We were able to re-examine ten of these. All ten were of Riseborough and Radin's (1969) types III or IV, the two most severe types (Table I). Five fractures were open. The average age was forty-nine years, the youngest patient being fourteen years and

TABLE I

\begin{tabular}{|c|c|}
\hline Type I & No displacement of the fragments \\
\hline Type II & $\begin{array}{l}\text { Trochlear and capitular fragments separated but not } \\
\text { appreciably rotated in the frontal plane }\end{array}$ \\
\hline Type III & Separation of fragments and significant rotatory deformity \\
\hline Type IV & $\begin{array}{l}\text { Severe comminution of the articular surface and wide } \\
\text { separation of the humeral condyle }\end{array}$ \\
\hline
\end{tabular}

the oldest eighty. The epiphyses were fused in the two youngest patients. The average follow-up period was two and a half years, the longest being four years and the shortest nine months. There is a limited amount of information from another surgeon about the patient we were unable to review.

\section{METHOD OF TREATMENT}

Open injuries were first cleaned and sutured, usually under a general anaesthetic. Manipulation was not performed routinely, but in patients given a general anaesthetic the opportunity was taken to mould the fragments into a better position. This never gave an accurate reduction and the position obtained was unstable.

Otherwise, no anaesthetic was used. The arm was supported in a collar-and-cuff sling with the elbow flexed as near to 120 degrees as the swelling and circulation allowed. Pendulum movements of the shoulder and active exercises of the fingers and wrist were begun immediately.

After a few days, when pain and swelling were subsiding, gentle active movements of the elbow were begun under the guidance of the physiotherapist. Passive movements were prohibited, but the patient was persuaded to increase gradually the range of elbow movement. As control of flexion was gained, the sling was lowered a little every three or four days until the elbow was supported at just below 90 degrees of flexion. 
At six weeks the fracture had usually united. The sling was then discarded but intensive active exercises were continued until the range of movement ceased to improve, usually after three or four months.

The fracture had been reduced by a combination of traction and moulding: traction exerted by the weight of the forearm and moulding of the fragments by early movements of the elbow.

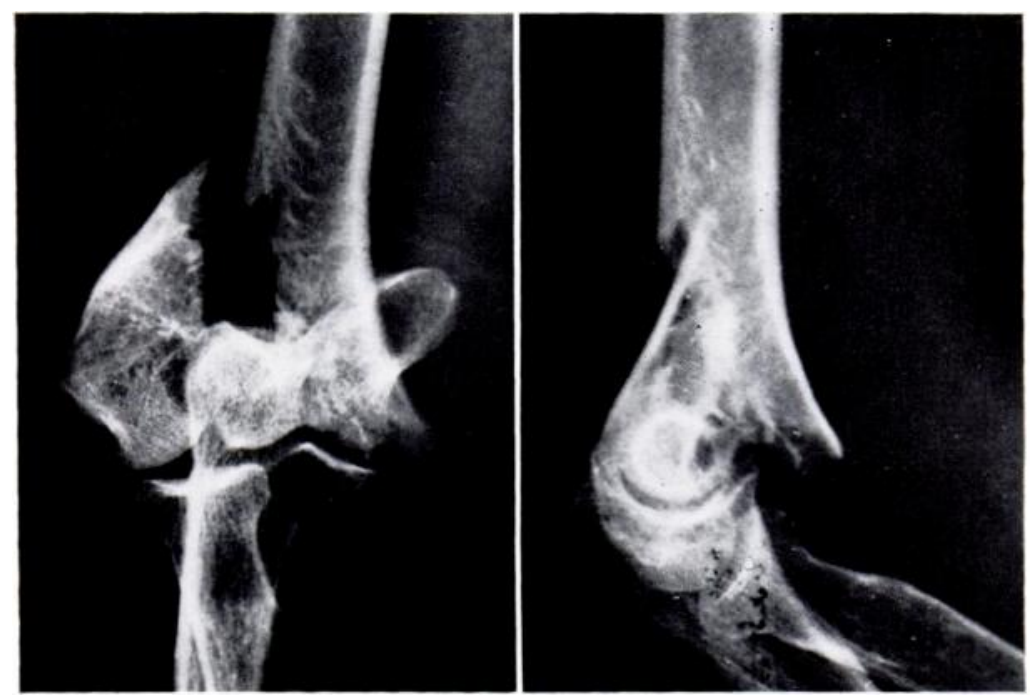

Fig. 1

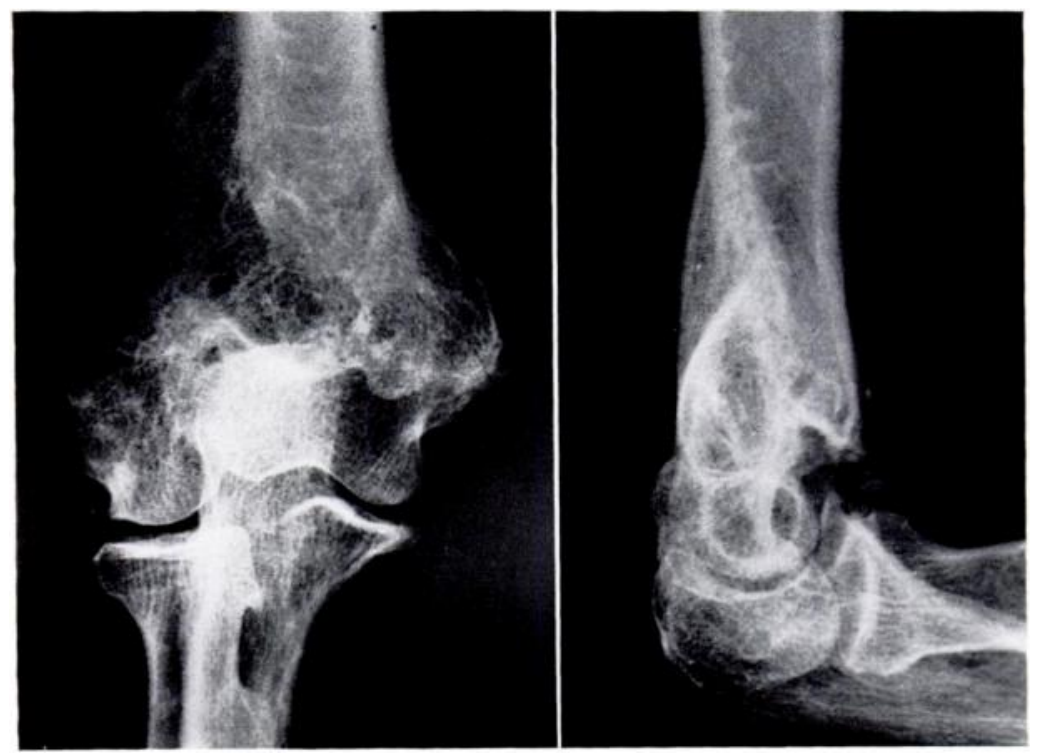

Fig. 2

Figure 1-Initial radiograph of T-shaped intercondylar fracture of humerus. Figure 2-Same case two years after treatment in a sling with active movements.

\section{RESULTS}

Reduction of the fracture was never completely accurate but the aim was good function rather than anatomical perfection. Some surprisingly good radiographic appearances were nevertheless obtained (Figs. 1 and 2). 
The average stay in hospital was five and a half days. One patient required convalescence for two months because of hemiplegia on the other side. The other patients remained in hospital mainly for physiotherapy. At follow-up, the range of flexion-extension at the elbow averaged 98 degrees; the stiffest elbow had 70 degrees and the most mobile 130 degrees (Table II). Rotation of the forearm was full in all cases.

TABLE II

Final Range of Movement (Ten Cases)

\begin{tabular}{|c|c|ccc|c|}
\hline $\begin{array}{c}\text { Case } \\
\text { number }\end{array}$ & $\begin{array}{c}\text { Age } \\
\text { (years) }\end{array}$ & $\begin{array}{c}\text { Closed } \\
\text { or open }\end{array}$ & $\begin{array}{c}\text { Arc of } \\
\text { movement } \\
\text { (degrees) }\end{array}$ & $\begin{array}{c}\text { Total range } \\
\text { of movement } \\
\text { (degrees) }\end{array}$ \\
\hline 1 & 80 & Open & $30-140$ & 110 \\
\hline 2 & 73 & Open & $30-135$ & 105 \\
3 & 69 & Closed & $15-140$ & 125 \\
4 & 64 & Open & $10-135$ & 125 \\
5 & 53 & Open & $45-130$ & 85 \\
6 & 50 & Closed & $40-110$ & 70 \\
7 & 42 & Closed & $45-115$ & 70 \\
8 & 31 & Open & $20-90$ & 70 \\
9 & 16 & Closed & $45-150$ & 105 \\
10 & 14 & Closed & $20-150$ & 130 \\
\hline
\end{tabular}

When reviewed, apart from some loss of flexion-extension, six patients were without symptoms; all of these were doing the same work as before their injury. Three other patients complained of an ache in the elbow in cold or damp weather; two of these had returned to their former work but the third had to change from heavy haulage driving to light van delivery work. The remaining patient had a gunstock deformity, the only varus or valgus deformity in the series. She had no symptoms apart from some loss of movement.

The interval between injury and return to full use of the arm was always four or five months. Two patients with office jobs were able to return to work long before this, and three others were able to perform light duties after two months.

The patient lost to follow-up had an open fracture and is reported to have 110 degrees of flexion-extension at the elbow. He had returned to work but had considerable pain in his arm, which was improved by removing two bony spikes from the lower humerus.

\section{DISCUSSION}

Treatment by early activity is only one of several methods used for T-shaped fractures of the lower humerus: others include manipulation under general anaesthetic followed by immobilisation in plaster; skeletal traction through the olecranon allowing active movement; and open reduction with internal fixation.

There are several advantages of treatment by a sling and active exercises. The patient is not confined to bed and can be treated as an out-patient. No anaesthetic is necessary unless the fracture is open. There is no risk of the wound infection reported by Decoulx, Decoulx, Hespeel and Decoulx (1964) after internal fixation, or of pin-track infection from skeletal traction, a complication described by Riseborough and Radin (1969) and by Conn and Wade (1961). Furthermore, the method can be used for all T-shaped intercondylar 
fractures except in the rare case complicated by unconsciousness prolonged for more than a few days; whereas one would hesitate to use internal fixation in open injuries or in very comminuted fractures, and some patients cannot tolerate skeletal traction for three weeks.

With 100 degrees of flexion-extension at the elbow, the ideal arc of movement is from 20 to 120 degrees. When the range is less than 100 degrees it is probably better to sacrifice extension in favour of flexion; this was agreed by all but one of our patients. The one patient who disagreed, whose range was from 20 to 90 degrees, preferred the arc he had. The injured arm in his case was not the dominant one, whereas in three other patients with a range of less than 100 degrees the dominant side was affected.

It is probably possible to organise a particular arc of movement by varying the initial position of the sling. However, flexion not gained in the first three weeks is not likely to be obtained subsequently, whereas extension may improve with active exercises over several months. Therefore, to obtain an adequate amount of flexion, the arm should be placed in the sling with the elbow as near to 120 degrees of flexion as possible in the first instance.

We have tried to compare our results with those treated by other methods. It is worth noting that all series are relatively small, most with less than twenty cases treated by the same method, and that all our fractures were of the two most severe types (Table I).

Eastwood (1937) reviewed fourteen patients with severe fractures treated by almost the same method. The results were similar to ours. Riseborough and Radin (1969) favoured skeletal traction through the olecranon and their results also were much the same. In their cases treated by internal fixation the results were inferior. Evans (1953) also obtained similar results to ours with his method of internal fixation, except for one patient who developed a stiff elbow.

Miller (1964) reported that manipulation and immobilisation in plaster gave an average of 47 degrees of elbow movement compared to 111 degrees obtained with internal fixation. This latter result is superior to the average in our series but some patients with supracondylar fractures that did not involve the elbow joint were included.

Although the results in this series are no better than some surgeons have obtained by internal fixation or skeletal traction, the smaller risk of producing a disastrously stiff and painful elbow and the several advantages of the method described make it attractive.

\section{SUMMARY}

1. A review of ten cases of $\mathrm{T}$-shaped intercondylar fractures of the humerus treated with a sling and early movement is presented.

2. The method and the results are discussed and some comparison is made with other series. 3. This method of treatment has certain advantages and the results are reasonable in comparison with those of other methods.

We are indebted to $\mathrm{Mr} \mathrm{A}$. Graham Apley and Mr Gordon Hadfield for allowing us to review their patients and for their help and encouragement.

\section{REFERENCES}

ConN, J., Jun., and WADE, P. A. (1961): Injuries of the Elbow: A Ten-year Review. Journal of Trauma, 1, 248. Decoulx, P., Decoulx, M., Hespeel, J., and Decoulx, J. (1964): Les fractures de l'extrémité inférieure de l'humérus chez l'adulte (152 cas). Revue de chirurgie orthopédique et réparatrice del' Appareil Moteur, 50, 263.

EASTwOod, W. J. (1937): The T-shaped Fracture of the Lower End of the Humerus. Journal of Bone and Joint Surgery, 19, 364.

Evans, E. M. (1953): Supracondylar-Y Fractures of the Humerus. Journal of Bone and Joint Surgery, 35-B, 381.

Miller, W. E. (1964): Comminuted Fractures of the Distal End of the Humerus in the Adult. Journal of Bone and Joint Surgery, 46-A, 644.

Riseborough, E. J., and Radin, E. L. (1969): Intercondylar T Fractures of the Humerus in the Adult. A Comparison of Operative and Non-operative Treatment in Twenty-nine Cases. Journal of Bone and Joint Surgery, 51-A, 130. 